\title{
A CRISE NA EDUCAÇ̃̃O, 60 ANOS DEPOIS: APONTAMENTOS SOBRE A CRISE EDUCACIONAL MODERNA NO QUADRO TEÓRICO DE A CONDIÇÃO HUMANA, DE HANNAH ARENDT
}

\author{
Wanderley José Deina ${ }^{*}$ \\ ORCID: https://orcid.org/0000-0001-5091-4781
}

RESUMO: $\mathrm{O}$ artigo $A$ crise na educação, publicado por Hannah Arendt em 1958, o mesmo ano em que lançou $A$ Condição Humana, apresenta uma análise singular acerca dos efeitos da crise política moderna manifesta em um contexto no qual a política, em seu sentido estrito, estaria de fora. Sessenta anos depois, o texto continua despertando reflexões importantes, demarcando a sua vitalidade, relevância e atualidade. O propósito deste trabalho é apresentar, na forma de um diálogo, alguns pontos nos quais a autora ancora sua singular interpretação acerca da educação moderna, na crise política geral apontada em $A$ Condição Humana. De um modo específico, busca relacionar as críticas à pedagogia com as mudanças epistemológicas e axiológicas produzidas pela ciência moderna e pela deterioração do espaço público, ratificando a importância das reflexões de Hannah Arendt sobre a educação e sobre a política.

Palavras Chave: Modernidade; Crise; Educação; Arendt.

THE CRISIS IN EDUCATION, 60 YEARS LATER: NOTES ON THE MODERN EDUCATIONAL CRISIS IN THE THEORETICAL FRAMEWORK OF HANNAH ARENDT'S THE HUMAN CONDITION

ABSTRACT: The article The crisis in education, published by Hannah Arendt in 1958 (the same year she launched The Human Condition) presents a singular analysis about the effects of the modern political crisis manifested in context where politics, in its strict sense, would be left out. Sixty years later, the article still wakens important reflections, marking its vitality, relevance and actuality. The purpose of this work is to present, in the form of a dialogue, some points in which the author anchors her singular interpretation about modern education, in the general political crisis pointed out in The Human Condition. Specifically, it seeks to relate criticisms

\footnotetext{
${ }^{1}$ Universidade Tecnológica Federal do Paraná, Curitiba, PR, Brasil.

"Graduado em Filosofia pela Universidade Federal do Paraná (UFPR), Doutor e Mestre em Educação pela Universidade de São Paulo (USP), Professor de Filosofia na Universidade Tecnológica Federal do Paraná (UTFPR) e do Mestrado Profissional em Filosofia (PROF-FILO), da Universidade Federal do Paraná, (UFPR). Atualmente, realiza 0 estágio de Pós-Doutorado na Faculdade de Educação da Universidade de São Paulo (FEUSP). Grupos de Pesquisa: Grupo de Estudos e Pesquisas em Filosofia e Ensino de Filosofia (FEF/UTFPR) e Grupo de Estudos e Pesquisas em Trabalho, Educação e Tecnologia (GETET/UTFPR). E-mail:<wdeina@utfpr.edu.br >.
} 
to pedagogy with the epistemological and axiological changes produced by modern science and the deterioration of public space, confirming the importance of Hannah Arendt's reflections on education and politics.

Keywords: Modernity; Crisis; Education; Arendt.

Em tempos de crise, muitos discursos dissonantes podem ocupar o palco do debate público, estabelecendo análises conceituais e oferecendo soluções diversas. Em grande medida, constituem-se a partir de critérios teóricos tradicionalmente estabelecidos, de modo a perpetuar as disputas ideológicas que possivelmente constituem, junto a outros fatores, a essência da própria crise. Os argumentos, filosóficos e científicos, são abundantes. Não faltam justificativas, enraizadas historicamente, a favor desta ou daquela posição, na luta para demarcar o terreno e ocupar o espaço. Não faltam também soluções criativas, apontando determinados caminhos e interditando outros possíveis. Em grande medida, os argumentos e justificativas também podem se revelar conceitualmente vazios. No caso específico da educação, talvez a pluralidade de discursos pedagógicos seja correlata à dos discursos ideológicos que existem no mundo; o que significa que a educação, no âmbito familiar ou escolar, não é um campo livre de tensões, alheio ao que se passa no mundo público. Na disputa pela ocupação do campo educacional, há muito mais do que um suposto conceito de eficiência pedagógica relacionado tão somente à qualidade da formação das crianças e jovens, como se o próprio conceito de qualidade não fosse constituído historicamente. Não por acaso, quando um governo é substituído por outro, as mudanças educacionais sejam tão recorrentes, mesmo nas democracias, e tão automáticas que se transformam em lugar comum. Em caso de golpe de estado, essas mudanças certamente tornam-se ainda mais céleres. Nesse sentido, a educação transformase em "instrumento da política e a própria atividade política" pode ser "concebida como uma forma de educação" (ARENDT, 2003, p. 225). Assim, a guerra permanente pela ocupação do campo educacional, em benefício de uma determinada visão de mundo, possibilita que o próprio mundo e seus habitantes sejam simplesmente ignorados, favorecendo concepções de formação restritas aos interesses momentâneos daqueles que detêm o poder institucional. De soluções "infalíveis", as cíclicas reformas educacionais podem tornar-se um fator que aprofunda e amplia os problemas que lhes serviram como justificativa, perpetuando a própria crise. 
Nos momentos de crise, quando o essencial parece submergir nas diversas tentativas fracassadas para estancar os problemas mais críticos, também podem emergir algumas vozes singulares, capazes de revelar uma compreensão mais ampla e também mais profunda acerca daquilo que está se passando. Tal amplitude e profundidade talvez só seja possível porque emanam de sujeitos que não se deixam seduzir facilmente pela novidade inerente ao discurso do progresso e que, ao mesmo tempo, não se prendem de maneira dogmática aos preconceitos derivados de antigas tradições que já se perderam no tempo. São pessoas capazes de conquistar "para si mesmas um presente, uma espécie de tempo sem tempo no qual os homens podem criar obras atemporais com que transcendam sua própria finitude (ARENDT, 2010b, p. 233). Através de sua obra, como uma espécie de farol, são capazes de iluminar o caminho dos navegantes arrastados pela correnteza das verdades messiânicas ou desorientados pela tormenta da incerteza, do desespero e da desconfiança com a humanidade. Certamente, o nome de Hannah Arendt está circunscrito neste grupo restrito de pessoas que deixaram o seu rastro de luz em alguns dos períodos mais sombrios da história. São autores que, mesmo vinculados de uma maneira mais incisiva a uma área específica do conhecimento, produzem algo tão significativo que conseguem extrapolar as suas fronteiras tradicionais. Por este motivo, costumamos tratá-los como clássicos.

Neste ano, duas importantes obras de Hannah Arendt completam sessenta anos de existência pública: A Condição Humana e $A$ crise na educação. A primeira ganhou uma repercussão mais ampla, sendo considerada por muitos especialistas seu livro mais importante. Nele a autora apresenta a sua nada comum interpretação acerca da crise geral que a civilização ocidental atravessa desde o início da modernidade, a partir de um vocabulário específico, que lhe permite dialogar com a tradição do pensamento filosófico e político com grande desenvoltura, liberdade e originalidade. Embora Arendt nunca tenha se reconhecido formalmente uma filósofa e nem se sentisse confortável com tal tratamento, talvez o seu caso seja um dos mais emblemáticos para a definição de Deleuze e Guattari do filósofo como "amigo do conceito" e como o "conceito em potência". Para os autores, isso "quer dizer que a filosofia não é uma simples arte de formar, de inventar ou de fabricar conceitos, pois os conceitos não são necessariamente formas, achados ou produtos. A filosofia, mais rigorosamente, é a disciplina que consiste em criar conceitos". Com uma citação de Nietzsche, os autores acrescentam: “os filósofos 
não devem mais contentar-se com os conceitos que lhes são dados para somente limpá-los e fazê-los reluzir, mas é necessário que eles comecem por fabricá-los, criá-los, afirmá-los, persuadindo os homens a utilizá-los" (DEULEUZE; GUATARRI, 2004, p. 13). Em grande medida, é o que Arendt pratica ao buscar a restituição do significado de conceitos fundamentais da política, ao subverter os diversos sentidos incorporados a eles pela tradição e ao criar um vocabulário original que define o sentido fundamental de sua própria filosofia. Em relação à segunda obra, $A$ crise na educação, trata-se de um artigo dirigido a uma área sobre a qual a autora fez questão de ressaltar que nada poderia saber de específico. Por tratar-se de um artigo entre tantos outros, alguém poderia questionar sobre a validade de considerá-lo uma obra clássica. O questionamento, em si mesmo, pode ser válido, mas a repercussão e a atualidade do texto, especialmente para a área da educação, demonstram sua importância, sua vitalidade e a obrigatoriedade de sua leitura especialmente para as pessoas diretamente envolvidas com a educação das crianças e dos jovens.

Uma característica que sobressai na obra de Hannah Arendt é a profunda coerência entre seus escritos. Embora, em grande parte, tenham causado polêmicas que ultrapassariam a linha do tempo de vida de seus interlocutores mais críticos, um olhar abrangente sobre aquilo que produziu permite constatar um esforço de construção teórica cujos alicerces permaneceram praticamente inabaláveis. O caráter singular de sua perspectiva interpretativa também é uma das fontes das diversas críticas que recebeu. Outra, talvez, esteja relacionada com a sua marcante personalidade, muitas vezes impetuosa e intempestiva, sobretudo quando se dedicava a questões específicas, de interesse público, cujo exemplo mais conhecido fora o julgamento de Eichmann. O fato é que Arendt não economizava nas tintas de tonalidades fortes para pintar os seus quadros. Seu amor pelo mundo manifestava-se com certa frequência na forma de contundentes críticas dirigidas a situações particulares que lhe causavam perplexidade. Estas características pessoais, de certo modo, são fundamentadas pela própria autora em $A$ Vida do Espírito, quando constrói uma "imagem poética" de Sócrates, um pensador, como se evidencia no texto, por quem nutria uma profunda admiração. Arendt cita uma frase atribuída ao filósofo grego, que poderia facilmente referir-se a ela própria: "Eu preferiria que minha lira ou um coro por mim dirigido desafinasse e produzisse ruído desarmônico e [preferiria] que multidões de homens discordassem de mim do 
que eu, sendo um viesse a entrar em desacordo comigo mesmo e a contradizer-me" (ARENDT, 2010b, p. 203). Para a autora, Sócrates representa um exemplo bem sucedido do pensador que não se isolava do mundo para elaborar suas considerações a respeito dele, ainda que a incompreensão pública lhe trouxesse riscos.

$\mathrm{O}$ ensaio $A$ Crise na Educação, publicado em inglês no mesmo ano em que a autora lançou $A$ Condição Humana, foi um dos momentos em que suas palavras, dirigidas a alguma situação específica do mundo, trouxeram, num primeiro momento, mais inquietação do que compreensão por parte de seus leitores. A própria autora procurou precaver-se das críticas, advertindo, no início do texto, sobre o fato de não se considerar uma especialista e que não seria aconselhável, "ao leigo, dar atenção a distúrbios em áreas das quais, em sentido especializado, ele pode nada saber (...)" (ARENDT, 2003, p. 222). Tal precaução pode revelar-se como mais uma estratégia inspirada na ironia socrática, a de afirmar inicialmente que nada saberia sobre um determinado assunto a ser discutido, para no final deixar os seus interlocutores atordoados com o tufão do pensamento que acabara de passar (ARENDT, 2010b, p. 188-216). Para um especialista desprevenido, é como se a leitura fosse acompanhada pelo próprio "moscardo socrático" a guiar uma implacável desconstrução dos conceitos hodiernos da educação. O espanto se torna inevitável, pois na mesma medida em que suas palavras parecem fazer sentido, não é possível encontrar referências conceituais que embasem sua crítica sem o conhecimento prévio de sua original interpretação acerca da crise geral que atingiu o mundo ocidental. Sobre este aspecto dos escritos educacionais de Hannah Arendt, Young-Bruhel destaca:

\footnotetext{
Quando Hannah Arendt escrevia ensaios como "Reflexões sobre Little Rock" e "A Crise na Educação", empregava o complexo esquema elaborado em "A condição humana", mas raramente se detinha para recapitular seus principais elementos. Sua impaciência abriu caminho para muitas incompreensões e ela era frequentemente tomada por uma pensadora fria e abstrata, quando na realidade estava dedicada a certo tipo de situação concreta. Ela chamou seu método filosófico de "análise conceitual"; sua tarefa era descobrir "de onde vêm os conceitos” (YOUNG-BRUHEL, 1997, p. 286).
}

Ainda no texto $A$ resposta de Sócrates, Arendt faz uma breve apresentação do método socrático que remete a esta descrição em sua biografia. Ao mesmo tempo, aproxima ainda mais a sua abordagem, especialmente nas questões mais controversas em que se envolveu, da imagem que ela própria construiu, pedindo uma "licença poética", acerca do filósofo ateniense. 
A introdução em geral é a seguinte: sem dúvida há pessoas felizes, atos justos, homens corajosos, belas coisas para se ver e admirar, como todos sabem; o problema reside em nossos substantivos, que são provavelmente derivados dos adjetivos que aplicamos todos os dias a casos particulares tais como nos aparecem (nós vemos um homem feliz, percebemos o ato corajoso ou a decisão justa). Em resumo, o problema começa com palavras como felicidade, justiça coragem e outras que hoje em dia chamamos de conceitos (...) (ARENDT, 2010b, p. 192).

Para além das críticas contundentes ao sistema educacional dos Estados Unidos, objeto principal de sua análise em $A$ crise na educação, Arendt procura desvelar o conceito de educação que subjaz a pedagogia moderna, tomada genericamente. Ao mesmo tempo, procura construir, ou restituir, um significado original de educação a partir de outros substantivos relacionados, tais como natalidade, autoridade, responsabilidade, tradição, senso comum, espaços público, privado e social, todos, de alguma forma, desenvolvidos em $A$ Condição Humana. Ainda assim, a compreensão de alguns aspectos de sua crítica exige a leitura de outros textos, anteriores ou posteriores ao artigo, que, de qualquer modo, não esgotam algumas das questões provocadas. Young-Bruhel destaca que, "com a ajuda da filologia ou da análise linguística", Arendt "retraçava o caminho dos conceitos políticos até as experiências históricas concretas e geralmente políticas que davam origem a tais conceitos", praticando "uma espécie de fenomenologia" cujo propósito seria "avaliar a que ponto o conceito se afastara de suas origens" (YOUGN-BRUHEL, 1997 , p. 286). Sua abordagem da crise, no papel de uma "estrangeira" em um campo no qual, a princípio, poderia nada saber de específico, parece indicar esse exercício de verificação conceitual.

É a oportunidade, proporcionada pelo próprio fato da crise - que dilacera fachadas e oblitera preconceitos -, de explorar e investigar a essência da questão em tudo aquilo que foi posto a nu, e a essência da educação é a natalidade, o fato de que seres nascem para o mundo. O desaparecimento de preconceitos significa simplesmente que perdemos as respostas em que nos apoiávamos de ordinário sem querer perceber que originariamente elas constituíam respostas a questões. Uma crise nos obriga a voltar às questões mesmas e exige respostas novas ou velhas, mas de qualquer modo, julgamentos diretos. Uma crise só se torna um desastre quando respondemos a ela com juízos pré-formados, isto é, com preconceitos. Uma atitude dessas não apenas aguça a crise como nos priva da experiência da realidade e da oportunidade por ela proporcionada à reflexão (ARENDT, 2003, p. 223).

A falta de referenciais teóricos específicos para tratar do tema educação pode causar certa perplexidade. O texto é dividido em quatro partes, das quais a segunda possivelmente seja a mais difícil 
de ser compreendida, ainda que se tenha um conhecimento prévio da obra da autora; ao mesmo tempo, é a que mais possui alusões à pedagogia moderna. Carregado de apontamentos imprecisos, ora voltados ao pragmatismo, ora à psicologia comportamentalista, ora misturando as duas coisas projetadas numa imagem genérica sob a máscara de pedagogia moderna, a impressão que se tem é a de que a autora não tem o menor interesse em esclarecer a que, ou a quais pedagogias exatamente estaria se referindo. Arendt parece estar preocupada apenas em indicar sobre quais pressupostos a educação moderna se constituiu, aproximando, indiretamente, as suas considerações sobre o sentido da formação escolar, nos Estados Unidos e na sociedade moderna como um todo, de suas elaborações teóricas desenvolvidas em $A$ Condição Humana. Assim, talvez não se trate de simples desconhecimento daquilo que ocorre no plano teórico específico, mas de uma escolha.

Observa-se logo no primeiro parágrafo que, com uma certa dose de ironia, Arendt chama atenção para "os perigos de um declínio sempre crescente nos padrões elementares na totalidade do sistema escolar", enfatizando que "a seriedade do problema tem sido sublinhada apropriadamente pelos inúmeros esforços baldados das autoridades educacionais para deter a maré" (ARENDT, 2003, p. 222, Grifo meu). O próprio título do artigo já indica que a autora não pretende aludir à crise como um problema específico da educação, mas analisar os efeitos $d a$ crise política geral que arrebatou o mundo moderno na área da educação. A escolha por uma abordagem a certa distância, ignorando ou generalizando deliberadamente as elaborações dos pesquisadores do campo específico ao qual se refere, soa mais como uma estratégia para preservar a própria autonomia das observações. Afinal, "o traço distintivo do pensamento arendtiano sempre foi sua radical independência e autonomia, pois, para ela, pensar sempre significou pensar por si mesma" (DUARTE, 2013, p. 42). Ademais, uma das críticas iniciais da autora se refere justamente ao fracasso das tentativas de estancar a crise na própria área, na medida em que ela é, geralmente, respondida com "juízos pré-formados" fundamentados na crença de que se estaria tratando de "problemas específicos confinados a fronteiras históricas e nacionais, importantes somente para os imediatamente afetados" (ARENDT, 2003, p. 222). Como parte do mundo, a educação não conseguiria passar ilesa aos diversos problemas decorrentes da crise geral que afetam a sociedade como um todo. Talvez por isso, uma de suas indicações para conter a crise na área da educação, em seu sentido escolar, seja tratá-la como 
um espaço distinto, entre o mundo privado e o mundo público, de tal modo que os problemas decorrentes dessas esferas da vida humana não invadam o campo da educação.

O principal conceito da reflexão arendtiana sobre a educação é a natalidade. Retirado de suas reflexões políticas em $A$ Condição Humana, o fato de novos seres chegarem ao mundo humano todos os dias na condição de estrangeiros, estabelece, do início ao fim do artigo, qual seria o sentido fundamental da educação. Como uma espécie de amálgama, a natalidade aproxima, relaciona, mas também diferencia as esferas pública e privada, instituindo a responsabilidade com o mundo como uma obrigação inerente a todas as pessoas adultas, especialmente aquelas diretamente envolvidas com a educação das crianças, ou seja, pais e professores. Da reponsabilidade, Arendt deriva a autoridade do educador, que em outros tempos, como no exemplo da educação romana (Ibid., p. 244), era praticamente automática, pois baseava-se em uma tradição iniciada com a fundação da república e que deixou de fazer sentido, no mundo ocidental, a partir da modernidade (Ibid., p. 243).

Em seu sentido animal, o nascimento de uma criança não difere da reprodução de outras espécies, determinado pela natureza biológica. "A criança partilha o estado de vir a ser com todas as coisas vivas; com respeito à vida e seu desenvolvimento, a criança é um ser humano em processo de formação, do mesmo modo que um gatinho é um gato em formação" (Ibid. p. 235). Por outro lado, a sua mundanidade, o fato de a criança ser lançada em um mundo constituído por objetos artificiais, construídos pelas mãos humanas (ARENDT, 2010a, p. 8), estabelece a necessidade de uma educação que lhe permita, em algum momento, exercer alguma profissão que possibilite a sua subsistência biológica. Além disso, a criança e o jovem também precisam adquirir o conhecimento da cultura, da língua, dos costumes e da história do mundo em que vivem, de modo a se orientarem politicamente e, ao mesmo tempo, responsabilizarem-se pela sua continuidade, na qualidade de adultos. Essa artificialidade da condição humana estabelece a educação como o meio a partir do qual nos tornamos efetivamente humanos, em condições de nos relacionarmos em um nível que transcenda ao dos nossos impulsos mais primitivos. Sem a intervenção educativa, nos equalizaríamos facilmente a qualquer outra espécie que encontramos na natureza. Enquanto os diversos animais são orientados pelos instintos naturais, biologicamente universalizados no quadro de cada espécie, a vida humana depende da educação para criar um sentido universal. 
Ela pode variar em sua forma e em seu sentido, de uma sociedade para outra, ou dentro de uma mesma sociedade dividida em classes distintas, o que é absolutamente lamentável, mas todas as formas de educação se referem à artificialidade da condição humana. O universal, no ser humano, pode ser interpretado como uma condição artificial que se materializa através da cultura de cada sociedade. A palavra cultura é tomada aqui no sentido mais amplo e genérico possível, sem considerar a complexidade do conceito.

No artigo $A$ crise na cultura: sua importância social e política, Arendt recorre à tradicional distinção romana entre "cultura no sentido de tornar a natureza um lugar habitável para as pessoas e cultura no sentido de cuidar dos monumentos do passado" que "ainda hoje determinam o conteúdo e o significado que temos em mente quando falamos de cultura" (ARENDT, 2003, p. 266). Para a autora, o significado de cultura não se esgota nestas definições. Referindose aos gregos, que não possuíam em seu vocabulário uma palavra correlata, alude à cultura como "o modo de relacionamento prescrito pelas civilizações com respeito às menos úteis e mais mundanas das coisas, às obras de artistas, poetas, músicos, filósofos e daí por diante" (Ibid. p. 267). Arendt também levanta o problema fundamental da relação entre "sociedade e cultura de massas". Em uma aproximação crítica às elaborações de Adorno e Horkheimer acerca da indústria cultural, sem mencioná-los evidentemente, a autora estabelece uma distinção entre a sociedade que depende da cultura e a sociedade de massas onde ela se torna um dos conceitos mais problemáticos e desafiadores para a educação: “a sociedade de massas (...) não precisa de cultura, mas de diversão, e os produtos oferecidos pela indústria de diversões são com efeito consumidos pela sociedade exatamente como quaisquer bens de consumo" (Ibid., p. 257). Arendt considera que "a cultura é ameaçada quando todos os objetos e coisas seculares, produzidos pelo presente ou pelo passado, são tratados como meras funções para o processo vital da sociedade, como se aí estivessem somente para satisfazer alguma necessidade - e nessa funcionalização é praticamente indiferente saber se as necessidades em questão são de ordem superior ou inferior" (Ibid., p. 261). Assim, a cultura, em um possível sentido filosófico, estético ou pedagógico, livre de qualquer determinação funcional que lhe possa ser atribuída, encontra grandes dificuldades na sociedade de consumo. Para a autora, a crença de que a sociedade de massas possa "se tornar mais 'cultivada' com o correr do tempo e com a obra da educação constitui (...) um fatal engano. $\mathrm{O}$ fato é que uma sociedade de consumo não pode absolutamente saber 
como cuidar de um mundo e das coisas que pertencem de modo exclusivo ao espaço das aparências mundanas, visto que sua atitude central ante todos os objetos, a atitude do consumo, condena à ruína tudo o que toca" (Ibid., p. 264).

Ao refletirmos sobre a cultura na realidade escolar, seja através do ensino da arte, da literatura ou da filosofia, pode-se perceber que frequentemente ela acaba sendo distorcida. Durante o processo formal de educação, quando a sedução pela beleza torna-se menos relevante que a necessidade imposta, através do sistema de ensino, do conhecimento instrumental para a aprovação nos disputados processos de seleção social, cujo exemplo mais evidente é o vestibular, a livre fruição estética e a reflexão crítica que a cultura poderia despertar são substituídas por uma espécie de taxonomia bizarra das obras de arte, da literatura e da experiência com o pensamento dos filósofos do passado. Com isso, o que se perde é a própria existência estética e filosófica, fazendo desaparecer uma parte fundamental de nossa mundanidade, talvez aquela que nos diferencie de um modo genuinamente significativo das demais espécies animais. Isso quando esses campos da cultura não são simplesmente suprimidos do currículo por decreto governamental, em benefício de outras áreas consideradas menos inúteis.

$\operatorname{Em} A$ Condição Humana, esta reflexão remete à preocupação com a permanência no mundo da atividade política, prerrogativa do homem da ação e do discurso, a menos tangível entre as atividades humanas: "os homens que agem e falam necessitam da ajuda do homo faber, em sua capacidade suprema, isto é, da ajuda do artista, dos poetas e historiadores, dos construtores de monumentos e escritores, porque sem eles o único produto da atividade dos homens, a estória que encenam e contam, de modo algum sobreviveria (ARENDT, 2010 a, p. 217). Através da materialidade da cultura, na forma das obras de arte e dos livros que permanecem no tempo, transcendendo em séculos ou milênios a vida biológica de quem os produziu ou os inspirou, as coisas mais abstratas ou imateriais, produzidas pelo pensamento ou pela ação humana, ganham permanência e significado. Deste modo, os próprios homens, autores ou personagens dessas obras do passado ou do presente, conseguem transcender a sua própria mortalidade, tornando-se relevantes para as gerações que lhes sucedem no tempo. Claude Lefort expressa de um modo bastante lúcido o sentido desta cultura para a humanidade:

A cultura se dá assim na forma de um diálogo. Um diálogo com os mortos, porém, com mortos que, desde o momento em que falam, desde que são levados a falar, 
estão mais vivos que os seres próximos, vivendo uma vida totalmente diferente, são imortais no espaço da humanidade, comunicam sua imortalidade àqueles que se voltam para eles aqui e agora" (LEFORT, 1999, p. 212).

A memória, materializada através da obra, torna-se uma parte importante e permanente do mundo. $\mathrm{Na}$ condição de personagens históricos, ou através das ideias que trouxeram ao espaço público - o lugar onde é possível equalizar, não o homem, mas o cidadão, congregando igualdade e diferença de modo a possibilitar a distinção -, alguns homens podem tornar-se imortais sem abrir mão de sua própria mundanidade. "A mortalidade dos homens reside no fato de que a vida individual, com uma história vital identificável desde o nascimento até a morte, advém da vida biológica" (ARENDT, 2010a, p. 22). Se não houvesse a possibilidade de a ação instituir-se neste ciclo natural, a vida humana não teria nenhum significado que a diferenciasse da vida de qualquer outra espécie.

Essa interpretação remete à cultura dos gregos antigos, tomada como modelo pela autora para distinguir imortalidade de eternidade. O conceito de eternidade, a partir da obra de Platão, ganhou repercussão social e política com o advento do cristianismo, fazendo com que os homens passassem a se preocupar apenas com a salvação individual da alma, abandonando, ou considerando de segunda ordem, o espaço público, o mundo que pode ser compartilhado por todos, santos ou pecadores. Desta fonte, possivelmente, deriva a conotação pejorativa dada, ainda em nossos dias, ao adjetivo mundano. Entre os gregos, que não conheciam o conceito de alma, as mais mundanas das atividades humanas ocupavam o centro da vida comunitária e eram realizadas como o meio a partir do qual alguns poderiam alcançar a grandeza e a imortalidade: a tarefa e a grandeza potencial dos mortais residem em sua capacidade de produzir
coisas - obras, feitos e palavras - que mereceriam estar e, pelo menos até certo
ponto, estão confortáveis na eternidade, de sorte que por meio delas os mortais
pudessem encontrar o seu lugar em um cosmo onde tudo é imortal exceto eles
próprios. Por sua capacidade de realizar feitos imortais, por poderem deixar atrás
de si vestígios imorredouros, os homens, a despeito de sua mortalidade individual,
atingem a imortalidade que lhes é própria e demonstram sua natureza "divina".
A diferença entre o homem e o animal aplica-se à própria espécie humana: só os
melhores (os aristor), que constantemente provam serem os melhores (aristeuein,
verbo que não tem equivalente em nenhuma outra língua) e que "preferem a fama
imortal às coisas imortais", são realmente humanos; os outros, satisfeitos com os
prazeres que a natureza lhes oferece, vivem e morrem como animais (Ibid., p. 23).
Confrontada a esta qualidade especificamente humana,
a aspiração à grandeza e à imortalidade, uma das dificuldades 
identificadas na educação dos Estados Unidos, que pode ser facilmente mal interpretada pelos leitores da área, está relacionada com o papel que o conceito de igualdade desempenha naquele país. A isonomia, um conceito político fundamental nas democracias, na compreensão da autora, pode trazer problemas de difícil resolução para o campo educacional. $\mathrm{Na}$ educação, ela se manifestaria numa espécie de equalização forçada entre professores e estudantes, entre os próprios estudantes e entre pais e filhos, atenuando ou fazendo desaparecer as suas diferenças fundamentais. O problema se originaria no próprio conceito moderno de igualdade, que abandonou o sentido estritamente político da palavra isonomia para aplicá-la à espécie humana, tomada universalmente. "Essa igualdade moderna, baseada no conformismo inerente à sociedade, e que só é possível porque o comportamento substituiu a ação como principal forma de relação humana, difere, em todos os seus aspectos, da igualdade dos tempos antigos, e especialmente da igualdade na cidade-Estado grega" (Ibid., p. 50). Arendt salienta que "a igualdade da polis grega, sua isonomia, era um atributo da polis e não dos homens, que recebiam sua igualdade em virtude da cidadania e não do nascimento" (ARENDT, 2011, p. 59). Evidentemente, não há nenhum posicionamento contra o tratamento igualitário estendido a todas as pessoas, considerando a dignidade humana em si mesma. Muito pelo contrário! O problema identificado, que se refere especificamente à área da educação, familiar ou a escolar, está na imposição de uma igualdade que procura apagar ou ofuscar todas as diferenças entre as pessoas:

\footnotetext{
o que torna a crise educacional na América tão particularmente aguda é o temperamento do país, que espontaneamente peleja para igualar ou apagar tanto quanto possível as diferenças entre jovens e velhos, entre dotados e pouco dotados, entre crianças e adultos e, particularmente, entre alunos e professores. É óbvio que um nivelamento deste tipo só pode ser efetivamente consumado às custas da autoridade do mestre ou às expensas daquele que é mais dotado, dentre os estudantes. Entretanto, é igualmente óbvio, pelo menos a qualquer pessoa que tenha tido algum contato com o sistema educacional americano, que essa dificuldade, enraizada na atitude política daquele país, possui também grandes vantagens, não apenas do tipo humano, mas também educacionalmente falando (2003, p. 229).
}

Essa preocupação é bastante complexa e relaciona-se a outros aspectos da condição humana no mundo moderno. A leitura isolada do tema, que ocupa uma parte significativa do texto, pode ocultar as complexas relações imbricadas em outros problemas identificados pela autora na educação moderna. O que entra em cena, de uma maneira difícil de ser detectada no texto sobre a educação, é o papel 
que o animal laborans, o trabalhador preocupado em produzir para o consumo imediato, passou a desempenhar a partir da modernidade. Para Arendt, apesar de necessário, seu trabalho não deixaria nada de permanente no mundo. Por ser motivado pelo critério exclusivo da necessidade, ele ainda incorpora uma grande capacidade destrutiva. $\mathrm{O}$ mundo humano é o conjunto de artefatos construídos pelo próprio homem, a obra erigida pelas mãos do homo faber, que não se confunde com o mundo natural. "A obra proporciona um mundo 'artificial' de coisas, nitidamente diferente de qualquer ambiente natural" (ARENDT, 2010a, p. 8). Apesar da distinção, a artificialidade da condição humana adquire tamanha proporção que a própria natureza pode ser concebida como uma extensão humana, sobrepujada através da técnica, assim como os próprios instrumentos tecnológicos criados pelo homem, sobretudo em nossos dias, podem ser entendidos como parte da natureza humana. Para Arendt, referindo-se ao animal laborans, a esse trabalhador que apenas responde às necessidades biológicas básicas, ainda que opere alguns dos instrumentos mais sofisticados concebidos pela tecnologia, "o fato é que nada pode ser mais facilmente e menos artificialmente mecanizado que o ritmo do processo do trabalho, que, por sua vez, corresponde ao ritmo repetitivo do processo vital, igualmente automático, e ao seu metabolismo com a natureza" (Ibid., p. 182). A partir da proeminência que ele veio a assumir, cuja funcionalidade social, voltada essencialmente para a produção dos objetos de consumo, supera qualquer possibilidade de transcendência através da ação e do discurso político, ou da fabricação de objetos úteis ou inúteis que tenham uma permanência maior do que a de seus criadores, Arendt interpreta:

O último estágio da sociedade de trabalhadores, o qual é a sociedade de empregados, requer de seus membros um funcionamento puramente automático, como se a vida individual realmente houvesse sido submersa no processo vital global da espécie e a única decisão ativa exigida do indivíduo fosse deixar-se levar, por assim dizer, a abandonar a sua individualidade, as dores e as penas de viver ainda sentidas individualmente, e aquiescer a um tipo de funcionamento, entorpecido e "tranquilizado" de comportamento (Ibid., p. 403).

Possivelmente seja em relação a esta característica das modernas sociedades de massas, que também se manifestaria no espaço escolar através de uma maneira específica de se educar, cujo sentido é essencialmente a funcionalidade social niveladora e automática, que a autora levanta os seus mais duros questionamentos em relação à educação dos Estados Unidos e à pedagogia moderna. A passagem a seguir deixa bastante evidente o seu incômodo: 
O motivo por que não foi atribuída nenhuma importância ao domínio que tenha o professor de sua matéria foi o desejo de levá-lo ao exercício contínuo da atividade de aprendizagem, de tal modo que ele não transmitisse, como se dizia, "conhecimento petrificado", mas ao invés disso, demonstrasse constantemente como o saber é produzido. A intenção consciente não era a de ensinar conhecimentos, mas sim inculcar uma habilidade, e o resultado foi uma espécie de transformação de instituições de ensino em instituições vocacionais que tiveram tanto êxito em ensinar a dirigir um automóvel ou a utilizar uma máquina de escrever, ou, o que é mais importante para a "arte" de viver, como ter êxito com outras pessoas e ser popular, quanto foram incapazes de fazer com que a criança adquirisse os pré-requisitos básicos normais de um currículo padrão (ARENDT, 2003, p. 232).

Um dos aspectos da crise geral, levantado pela autora na segunda metade de $A$ Condição Humana, refere-se às mudanças epistemológicas decorrentes daquilo que ela trata como a "descoberta do ponto de vista arquimediano" e como o "advento da dúvida cartesiana" (ARENDT, 2010a), cuja repercussão se fez sentir em todas as esferas da vida em sociedade. Referindo-se ao método cartesiano, que teria sido concebido como uma resposta imediata às perplexidades ocasionadas pelas descobertas de Galileu, a autora afirma que "embora não se possa conhecer a verdade como algo dado e desvelado, o homem pode, pelo menos, conhecer o que ele próprio faz". Fundamentada na interpretação de Whitehead, Arendt entende que "a razão cartesiana baseia-se inteiramente 'no pressuposto de que a mente só pode conhecer aquilo que ela mesma produziu e retém de alguma forma dentro de si mesma"' (Ibid., p. 352). Seguindo nesta mesma linha, aponta para o desaparecimento do senso comum, um dos fundamentos para sua explicação tanto da crise política moderna em $A$ Condição Humana, como também para $A$ crise na educaşão.

Em relação à educação, há dois apontamentos específicos acerca das inovações pedagógicas. A primeira seria a substituição do aprendizado pelo fazer, a partir da qual o conhecimento de um professor se tornaria irrelevante para o processo de formação da criança, considerando que o próprio processo seria o foco principal das atividades. Neste caso, não se trataria de educação, mas de treinamento, ou seja, do desenvolvimento de habilidades específicas voltadas ao sistema produtivo e à funcionalidade social. Para a autora, a educação propriamente, "ao contrário da aprendizagem, precisa ter um final previsível", pois "visa introduzir o jovem no mundo como um todo" e não "em um segmento limitado e particular dele". O que significa que, ao final do processo de educação - que em seu sentido amplo, coincidiria "com o diploma colegial" (ARENDT, 2003, p. 246) 
-, o jovem precisaria sair formado com uma visão geral acerca do mundo em que vive. O sentido dessa formação é a autonomia política, que não deve se confundir com qualquer tipo de habilidade técnica, que possa ser adquirida através do treinamento vocacional. O segundo apontamento seria a substituição do trabalho pelo brincar, que promoveria uma espécie de retenção artificial da criança no universo infantil. Para a autora, a infância constitui uma etapa temporária do desenvolvimento humano e o brincar seria o modo propriamente infantil de se comportar, "que brota espontaneamente de sua existência. (...) A atividade característica da criança, pensava-se, está no brinquedo; a aprendizagem no sentido antigo, forçando a criança a uma atitude de passividade, obrigava-a a abrir mão de sua própria atitude lúdica" (Ibid., p. 232). Deste modo, crescer e tornar-se um adulto pressupõe o abandono gradativo da infância compelido pelos adultos, possibilitando aos jovens assumir a responsabilidade pelo mundo. Para a autora, "seja qual for a conexão entre fazer e aprender e qualquer que seja a validez da fórmula pragmática, sua aplicação à educação, ou seja, ao modo de aprendizagem da criança, tende a tornar absoluto o mundo da infância" (Ibid., p. 233). Assim, o universo infantil pode transformar-se em um mundo à parte, ao qual o adulto não tem acesso, privando, ao mesmo tempo, a criança do conhecimento acerca do que seja, efetivamente, o mundo adulto para além do exercício de alguma função específica. "Essa retenção da criança é artificial porque extingue o relacionamento natural entre adultos e crianças, o qual, entre outras coisas, consiste do ensino e da aprendizagem, e porque oculta ao mesmo tempo o fato de que a criança é um ser humano em desenvolvimento, de que a infância é uma etapa temporária, uma preparação para a condição adulta" (Ibid., p. 233). Embora Arendt não indique nenhuma referência para essa reflexão sobre a utilização pragmática do brinquedo e da brincadeira na educação, certamente ela se inspira nas elaborações de Walter Benjamin, que atribui ao processo de industrialização a responsabilidade pela transformação dos objetos e das atividades infantis que, em outros tempos, brotavam espontaneamente da criança.

A criança quer puxar alguma coisa e se transforma em cavalo, quer brincar com areia e se transforma em pedreiro, quer se esconder e se transforma em bandido e policial. Conhecemos bem alguns instrumentos de brincar, extremamente arcaicos e alheios a qualquer máscara ideacional (apesar de terem sido na origem, presumivelmente, de caráter ritual): bola, arco, roda de penas, papagaio - verdadeiros brinquedos, "tanto mais verdadeiros quanto menos dizem aos adultos”. Pois quanto mais atraentes são os brinquedos, no sentido usual, mais 
se afastam dos instrumentos de brincar; quanto mais eles imitam, mais longe eles estão da brincadeira viva. (...) A criança não é nenhum Robinson, as crianças não constituem nenhuma comunidade separada, mas são partes de povo e da classe a que pertencem. Por isso, o brinquedo infantil não atesta a existência de uma vida autônoma e segregada, mas é um diálogo mudo, baseado em signos, entre a criança e o povo (BENJAMIN, 1985, p. 247).

A tendência a uma separação artificial entre adultos e crianças no processo de educação, que interditaria o relacionamento natural entre as gerações, teria raízes mais antigas do que o início da pedagogia moderna e aspirações políticas talvez mais devastadoras. Arendt cita Rousseau e Platão de uma maneira aparentemente descolada de suas críticas à pedagogia predominante nos Estados Unidos, referindo-se ao "papel desempenhado pela educação em todas as utopias políticas, a partir dos tempos antigos", cuja pretensão sempre fora a fabricação de um mundo ideal a partir das crianças. A autora conclui suas críticas, afirmando, entre outras coisas, que "quem desejar seriamente criar uma nova ordem política mediante a educação, isto é, nem através da força e coação, nem através da persuasão, se verá obrigado à pavorosa conclusão platônica: o banimento de todas as pessoas mais velhas do Estado a ser fundado" (ARENDT, 2003, p. 225). No parágrafo seguinte, afirma que "tudo isso de modo algum ocorre na América, e é exatamente esse fato que torna tão difícil julgar aqui corretamente esses problemas" (Ibid., p. 226). Será? De fato, Arendt reconhece que, a partir da sua origem histórica e de sua condição de permanente polo de imigração, a educação dos Estados Unidos acaba tendo que oferecer às crianças que chegam ao país diariamente na condição de imigrantes uma formação completamente diferente daquela recebida na esfera familiar, o que é absolutamente compreensível. Por outro lado, esta necessidade acaba colaborando com uma espécie de distorção do sentido da educação, de um modo geral:

O papel político que a educação efetivamente representa em uma terra de imigrantes, o fato de que as escolas não apenas servem para americanizar as crianças, mas afetam também a seus pais, e de que aqui as pessoas são de fato ajudadas a se desfazerem de um mundo antigo e a entrar em um novo mundo, encoraja a ilusão de que um novo mundo está sendo construído mediante a educação das crianças. (Ibid., p. 226).

Por sua vez, as referências a Platão e a Rousseau não estão descoladas da crítica empreendida ao sentido geral da educação moderna, a partir daquilo que é identificado na educação dos Estados Unidos. O phatos do novo, inscrito até mesmo na moeda americana, novus ordo seclorum, uma nova ordem no mundo, representaria uma 
ilusão, que se materializaria através da educação das crianças, de que um mundo novo pode ser construído através da educação. Essa mentalidade teria possibilitado a aceitação acrítica de "modernas teorias educacionais originárias da Europa Central" que, na interpretação da autora, se consistiriam "de uma impressionante miscelânea de bom senso e absurdo levada a cabo, sob a divisa da educação progressista", permitindo "uma radical revolução em todo sistema educacional". Para Arendt, mesmo o novo mundo ao qual as crianças são introduzidas é sempre um mundo velho, "construído pelos vivos e pelos mortos", sendo novo apenas "para os que acabaram de penetrar nele pela imigração (Ibid., p. 226). No caso específico, o que está implícito a toda a discussão levantada não se relaciona, necessariamente, com a construção de um novo corpo político, com a fundação de um novo Estado através da educação das crianças, mas com a destruição do senso comum pressuposta nela.

Em A Condição Humana, há uma análise profunda acerca da transformação da ação política em uma modalidade da fabricação, a atividade do homo faber. Para a autora, a modernidade, de fato, criou os meios necessários à construção das utopias que seguem o exemplo platônico (ARENDT, 2010a, p. 274-294). Embora aquela análise seja importante para a compreensão de suas críticas à educação moderna, o problema fundamental da separação entre adultos e crianças, suscitado a partir do exemplo da educação política nos Estados Unidos, é essencialmente o desaparecimento do senso comum, decorrente da incorporação de determinados pressupostos da ciência moderna implícitos à pedagogia, mas também de uma mentalidade cristalizada na cultura americana, anterior à própria revolução. Embora Arendt preste grande reverência à fundação de novos corpos políticos, cujo único exemplo bem sucedido, considerado por ela na modernidade, seja a Revolução Americana (ARENDT, 2011), o aspecto do espírito revolucionário relacionado à ideia de que a novidade possui certa prerrogativa pode trazer grandes problemas políticos e dificuldades educacionais. Nos Estados Unidos, pelas suas características específicas em torno do phatos da novidade, de o espírito revolucionário ainda vivo pretender criar permanentemente uma nova ordem no mundo, o futuro pode facilmente ser estabelecido como referência praticamente absoluta, contraposto a um passado que, embora glorioso, pode tornar-se irrelevante ou ser simplesmente esquecido. ${ }^{1} \mathrm{~A}$ crise da educação americana, neste sentido, é um fenômeno que revela a grande abrangência da crise nas instituições tradicionais que fundamentavam a vida no ocidente até o início da modernidade. 
A questão do desaparecimento do senso comum é recorrente na obra de Hannah Arendt. Em uma interpretação que percorre um caminho contrário ao do espírito científico moderno, que tornou o senso comum um dos principais obstáculos para o conhecimento considerado verdadeiro, a autora identifica no seu desaparecimento um dos principais elementos para a dissolução do espaço público e para o desaparecimento da política, a atividade que congrega a pluralidade humana. Para a autora, o senso comum representa o mundo comum a todos, que determina a identidade da realidade objetiva do mundo como sendo algo compreensível a todas as pessoas. Trata-se de uma espécie de espírito coletivo que constituiria a base do juízo político, possibilitando ao indivíduo julgar adequadamente aquilo que aparece em público, mesmo que as coisas sejam vistas e interpretadas de perspectivas diferentes. A seguinte passagem de $A$ Condição Humana é bastante esclarecedora: "Somente quando as coisas podem ser vistas por muitas pessoas em uma variedade de aspectos, sem mudar de identidade, de sorte que os que estão à sua volta sabem que veem identidade na mais completa diversidade, pode a realidade do mundo aparecer real e fidedignamente" (ARENDT, 2010a, p. 70). Em $A$ Vida do Espirito, Arendt aprofunda esta conceituação, definindo o senso comum como "uma espécie de sexto sentido" a orientar a compreensão comum que temos do mundo, quando ele nos aparece através da experiência sensorial:

\begin{abstract}
a realidade do que percebo é garantida por seu contexto mundano, que inclui outros seres que percebem como eu; por outro lado, ela é percebida pelo trabalho conjunto de meus cinco sentidos. O que, desde São Tomás de Aquino, chamamos de senso-comum, sensus-communis, é uma espécie de sexto sentido necessário para manter juntos meus cinco sentidos, para garantir que é o mesmo objeto que vejo, toco, provo, cheiro e ouço; é a 'mesma faculdade [que] se estende a todos os objetos dos cinco sentidos. Esse mesmo sentido, um "sexto sentido" misterioso, porque não pode ser localizado como um órgão corporal, vai adequar as sensações de meus cinco sentidos estritamente privados - tão privados que as sensações, em sua qualidade e intensidade meramente sensoriais, são incomunicáveis - a um mundo comum compartilhado pelos outros" (ARENDT, 2010b, p. 67).
\end{abstract}

Referindo-se ao sistema educacional dos Estados Unidos, a autora interpreta que, sob a influência de determinadas experiências europeias, limitadas a algumas instituições educacionais que influenciaram no máximo alguns bairros próximos, "há cerca de vinte e cinco anos", foram empreendidas mudanças que derrubaram "completamente, como que de um dia para o outro, todas as tradições e métodos estabelecidos de ensino e de aprendizagem" (ARENDT, 2003 , p. 227). Sem entrar em detalhes sobre a quais experiências estaria se referindo, ${ }^{2}$ a autora avalia: 
O fato é que, por causa de determinadas teorias, boas ou más, todas as regras do juízo humano normal foram postas à parte. Um procedimento como esse possui sempre grande e perniciosa importância, sobretudo em um país que confia em tão larga escala no bom senso em sua vida política. Sempre que, em questões políticas, o são juízo humano fracassa ou renuncia à tentativa de fornecer respostas, nos deparamos com uma crise; pois essa espécie de juízo é, na realidade, aquele senso comum em virtude do qual nós e nossos cinco sentidos individuais estão adaptados a um único mundo comum a todos nós, e com a ajuda do qual nele nos movemos. O desaparecimento do senso comum nos dias atuais é o sinal mais seguro da crise atual. Em toda crise, é destruída uma parte do mundo, alguma coisa comum a todos nós. A falência do bom senso aponta, como uma vara mágica, o lugar em que ocorreu esse desmoronamento (Ibid., p. 227).

Arendt interpreta que a perda do senso comum teve a sua origem quando, diante das perplexidades causadas pelas descobertas científicas de sua época, René Descartes buscou refúgio em sua própria consciência para o estabelecimento de um ponto seguro para o conhecimento humano. Sua reflexão considera que, quando o sujeito, na condição de um indivíduo isolado de todos os outros, passou a bastar-se a si mesmo para o conhecimento da verdade, separado da própria realidade sensível do mundo, habitando através do pensamento uma outra realidade existente apenas em sua própria mente, o conhecimento compartilhado, que relacionava homens e objetos entre si na forma de um senso comum, tornou-se irrelevante.

O que os homens têm agora em comum não é o mundo, mas a estrutura de suas mentes, e isso eles não podem, a rigor ter em comum; o que pode ocorrer é apenas que a faculdade de raciocínio seja a mesma para todos. O fato de que, dado o problema de dois mais dois, todos chegaremos à mesma resposta, quatro, passa a ser de agora em diante o modelo máximo do raciocínio do senso comum" (ARENDT, 2010a, p. 353)

Ainda em A Condição Humana, a autora considera que o espírito cartesiano fora incorporado pelas filosofias políticas que se seguiram, cujo exemplo significativo mais imediato seria o de Hobbes, que em sua teoria política substituiu a ação pelo cálculo matemático e pelas leis da estatística. $\mathrm{Na}$ medida em que esse espírito foi avançando na modernidade, surgiu a economia, uma ciência específica que passou a administrar os estados nacionais a partir de critérios estritamente técnicos.

A perda do senso comum, um elemento essencial para a relação política entre as pessoas de todas as gerações, estabelece problemas específicos no campo educacional. Um deles teria sido o desaparecimento da autoridade na relação entre pais e filhos e entre professores e estudantes. Evidentemente, há outros fatores relacionados ao problema, indicados pela autora na sua interpretação, 
tais como a quebra do fio da tradição que manteve o mundo ocidental coeso em relação à compreensão política da realidade, desde a fundação da República Romana até o início da modernidade: "a crise da autoridade guarda a mais estreita conexão com a crise da tradição, ou seja, com a nossa atitude face ao âmbito do passado" (ARENDT, 2003, p. 243). A autora salienta que não é possível mais reestabelecer essa conexão, por isso, relaciona o estabelecimento da autoridade na educação, nas condições dispostas na modernidade, com a responsabilidade assumida pelo educador em relação ao mundo em que vive, especialmente quando está diante de uma criança. A própria preservação do mundo, do artifício humano, dependeria desta relação.

A autoridade do educador e as qualificações do professor não são a mesma coisa. Embora certa qualificação seja indispensável para a autoridade, a qualificação, por maior que seja, nunca engendra por si só a autoridade. A qualificação do professor consiste em conhecer o mundo e ser capaz de instruir os outros acerca deste, porém sua autoridade se assenta na responsabilidade que ele assume por este mundo. Face à criança, é como se ele fosse um representante de todos os habitantes adultos, apontando os detalhes e dizendo à criança Isso é o nosso mundo (Ibid., p. 239).

Para Arendt, "o mundo, visto que feito por mortais, se desgasta, e dado que os seus habitantes mudam continuamente, corre o risco de tornar-se mortal como eles. Para preservar o mundo contra a mortalidade de seus criadores e habitantes, ele deve ser, continuamente, posto em ordem" (Ibid., p. 243). O problema é que, em sua versão funcionalista, a educação desconsidera, ou, no mínimo, diminui significativamente a importância da relação do presente com o passado. Para além do conhecimento científico e dos objetos técnicos e tecnológicos, proeminentes na educação moderna, o mundo humano também é constituído de elementos menos palpáveis, ou seja, a cultura em seu sentido não prático ou inútil, conforme a definição levantada anteriormente. Quanto mais sofisticada for a artificialidade da sociedade, mais se torna dependente da educação e quanto menos atenção ela receber por parte dos velhos habitantes do mundo, menos vai dizer aos novos habitantes que chegam ao nosso mundo todos os dias através do nascimento. Por isso, Arendt é categórica: "qualquer pessoa que se recuse a assumir a responsabilidade coletiva pelo mundo não deveria ter crianças, e é preciso proibi-la de tomar parte em sua educação" (Ibid. p. 239).

A vida de Hannah Arendt transcorreu num período em que ocorreram duas guerras mundiais, sendo testemunha histórica do extermínio seletivo de milhares de seres humanos nos campos de 
concentração nazistas, de um grupo humano específico ao qual ela própria pertencia. Por muito pouco o seu destino não foi o mesmo. Como decorrência da profunda instabilidade do período histórico em que viveu, pelas diversas vicissitudes que o surgimento do nacional socialismo ocasionou na sua vida pessoal, escolheu não ter filhos. Quando a sua vida voltou a uma condição na qual trazer uma criança ao mundo não seria visto como um ato de profunda irresponsabilidade, vivendo nos Estados Unidos depois de ser expatriada da Alemanha, sua terra natal, já havia ultrapassado a idade biológica em que isso lhe seria permitido (YOUNG-BRUHEL, 1997). Arendt também não se considerava uma educadora profissional, se mantivermos em vista o seu conceito de que a educação se encerra quando os jovens concluem o colegial, devendo estar preparados para ocupar seu lugar no mundo adulto. Embora tenha sido professora universitária, a partir de seus próprios princípios, essa condição lhe excluiria da definição estrita daquilo que seja uma educadora. Por isso, a sua principal manifestação teórica acerca da educação é precedida de uma ressalva, de que estaria referindo-se a uma área na qual, vista por quem é de dentro, poderia ser considerada uma "estrangeira". Porém, uma tal acusação seria desconstruída facilmente a partir da grande relevância dada pela autora à área da educação para o mundo compartilhado por todos, ou seja, para o espaço público. Este, afinal, é o seu principal interesse:

\footnotetext{
Uma crise na educação em qualquer ocasião originaria séria preocupação, mesmo se não refletisse, como ocorre no presente caso, uma crise e uma instabilidade mais gerais na sociedade moderna. A educação está entre as atividades mais elementares e necessárias da sociedade humana, que jamais permanece tal qual é, porém se renova continuamente através do nascimento, da vinda de novos seres humanos (ARENDT, 2003, p. 234).
}

Portanto, não se trata de simples exercício de verificação conceitual, mas de uma preocupação legítima que deveria ser compartilhada por todas as pessoas adultas, especialistas em educação ou não. "O que nos diz respeito, e que não podemos portanto delegar à ciência específica da pedagogia, é a relação entre adultos e crianças em geral, ou, para colocá-lo em termos mais gerais e exatos, nossa atitude face ao fato da natalidade: o fato de todos nós virmos ao mundo ao nascermos e de ser o mundo constantemente renovado mediante o nascimento" (Ibid., p. 247).

Para Arendt, as três atividades humanas fundamentais que os homens realizam durante o seu período de vida na Terra, o trabalho, a obra e a ação, sobre as quais discorre ao longo de $A$ Condição 
Humana, "são relacionadas com a condição mais geral da existência humana: o nascimento e a morte, a natalidade e a mortalidade" (ARENDT, 2010a, p. 10). O nascimento e a morte dizem respeito ao indivíduo humano circunscrito em seu próprio ciclo biológico, enquanto a natalidade e a mortalidade se referem a esse mesmo indivíduo em uma condição compartilhada com todos os outros indivíduos humanos, sob o signo da humanidade. Esta condição nos diferencia de todas as demais espécies, demarcando o significado fundamental da educação, não simplesmente para o indivíduo. "Se a criança não fosse um recém-chegado nesse mundo humano, porém simplesmente uma criatura viva ainda não concluída, a educação seria apenas uma função da vida e não teria que consistir em nada além da preocupação para com a preservação da vida e do treinamento e na prática do viver que todos os animais assumem em relação aos seus filhos" (ARENDT, 2003, p. 235).

O problema que Hannah Arendt percebe na educação moderna, tomada genericamente a partir do exemplo dos Estados Unidos, está no fato de referir-se fundamentalmente à obra humana em seu sentido utilitário imediato. Por tratar-se de um fator condicionante da existência humana voltado, principalmente, para a funcionalidade social, ao invés de distinguir o humano do animal, a educação parece pretender equalizá-los. Um indivíduo "bem educado" pode perfeitamente operar o instrumento tecnológico mais sofisticado concebido pelo engenho humano, ou tomar decisões econômicas que afetem o mundo inteiro, decidindo sobre a vida e a morte de outros indivíduos, a partir de critérios exclusivamente técnicos apreendidos durante o processo de educação formal. Para isso, ele não precisa saber poesia, conhecer a história ou filosofar sobre os valores humanos intrínsecos à sua decisão. Mas o conhecimento técnico e os instrumentos tecnológicos, em si mesmos, não nos distinguem das demais espécies animais. $\mathrm{O}$ fato simples de possibilitarem ao animal homem um certo domínio sobre os demais animais que existem na natureza pode significar muito mais uma equalização do que propriamente uma distinção. Entre todas as espécies na natureza também há competição, há domínio e há aniquilação.

A natalidade aparece em $A$ Condição Humana como um conceito chave que oferece à humanidade a oportunidade de recomeçar, ainda que esteja mergulhada em uma crise profunda. "Prosseguindo na direção da morte, o período de vida do homem arrastaria inevitavelmente todas as coisas humanas para a ruína e a destruição, se não fosse a faculdade humana de interrompê-lo e iniciar algo novo" (ARENDT, 2010a, p. 
307). A partir disso, a pergunta essencial que se pode inferir de toda a discussão levantada ao longo do artigo $A$ crise na educação é sobre como estamos lidando com a condição humana da natalidade, com o fato de trazermos ao mundo todos os dias novos seres humanos que, apesar de não terem pedido para nascer, são lançados ao universo humano, tornando-se uma parte constitutiva dele.

Diferentemente dos entes naturais ou artificiais que existem no mundo, o indivíduo humano é definido, essencialmente, pelo substantivo ser que, por sua vez, constitui um verbo fundamental na maioria das línguas faladas pelos humanos. Para Heidegger, um pensador que exerceu grande influência sobre a filosofia de Hannah Arendt e que está presente nas reflexões da autora sobre a condição humana (DUARTE, 2000), o ser do homem não é algo dado a partir de uma essência ou de uma natureza que o antecede, apesar de já existir um mundo constituído quando de sua chegada. Existencialmente falando, o ser do homem se define enquanto dasein, como uma "presença" no mundo: "do ponto de vista ôntico, ela se distingue pelo privilégio de, em seu ser, isto é, sendo estar em jogo seu próprio ser" (HEIDEGGER, 1998, p. 38). Assim, sendo, o ser do homem se define na condição de um verbo que se põe em movimento num mundo constituído por outros entes e que, ao mesmo tempo, indica a presença humana e o seu pertencimento ao mundo: "o ser com os outros pertence ao ser da pre-sença que, sendo, está em jogo seu próprio ser. Enquanto ser-com, a presença 'é', essencialmente, em função dos outros" (Ibid., p. 175). Embora o sentido do ser, em Heidegger, seja remetido ao ser que busca seu próprio sentido ao longo de sua existência particular, algo que se encerra com a morte, tal presença e pertencimento ao mundo tem como ponto de partida o nascimento. Para Arendt, essa experiência singular deixa de ser estritamente fenomenológica a partir da possibilidade do ser, na condição de agente em meio a outros agentes, transcender a finitude de sua própria existência através de seus atos e de suas palavras, singulares e pessoais, dirigidas ao mundo. Nesse sentido, nossa experiência existencial particular pode torna-se política. Se em Heidegger, o próprio ser pode se perder de si mesmo no cotidiano - manifestando uma vida inautêntica, no ser-com os outros -, para Arendt é na convivência com a pluralidade de seres singulares que um indivíduo pode mostrar quem é, embora ele próprio possa conceber uma imagem diferente de si mesmo. No espaço público, escreve Arendt, “é quase certo que o 'quem', que aparece tão clara e inconfundivelmente para os outros, permanece oculto para a própria 
pessoa, à semelhança do daimon, na religião grega, que acompanha cada homem durante toda sua vida, sempre observando por detrás, por cima de seus ombros, de sorte que só era visível para aqueles que ele encontrava" (ARENDT, 2010a, p. 224). Por isso, a autora também considera que o aparecimento público de uma pessoa constitui uma espécie de segundo nascimento.

É com palavras e atos que nos inserimos no mundo humano, e essa inserção é como um segundo nascimento, no qual confirmamos e assumimos o fato simples do nosso aparecimento físico original. Não nos é imposta pela necessidade, como o trabalho, nem desencadeada pela utilidade, como a obra. Ela pode ser estimulada pela presença de outros a cuja companhia possamos desejar nos juntar, mas nunca é condicionada por eles; seu impulso surge do começo que veio ao mundo quando nascemos e ao qual respondemos quando começamos algo novo por nossa própria inciativa (Ibid., p. 223).

Nas sociedades de massas, a possibilidade de distinção pessoal, através da ação e do discurso políticos, tornou-se rara. A dissolução das esferas pública e privada, em benefício daquilo que na modernidade passou a ser chamando de sociedade, permitiu que a ação fosse substituída pela fabricação de corpos políticos, a pluralidade pela padronização do comportamento através da educação e dos mecanismos de controle social e o discurso, pelas leis da ciência econômica. Porém, o fato da natalidade permanece, ainda que de uma maneira paradoxal:

O novo sempre acontece em oposição à esmagadora possibilidade das leis estatísticas e à sua probabilidade que, para todos os fins práticos e cotidianos, equivale à certeza; assim, o novo sempre aparece na forma de um milagre. $\mathrm{O}$ fato de o homem ser capaz de agir significa que se pode esperar dele o inesperado, que ele é capaz de realizar o infinitamente improvável. E isso, mais uma vez, só é possível por que cada homem é único, de sorte que, a cada nascimento, vem ao mundo algo singularmente novo. Desse alguém que é único pode-se dizer verdadeiramente que antes dele não havia ninguém. Se a ação, como início corresponde ao fato do nascimento, se é a efetivação da condição humana da natalidade, o discurso corresponde ao fato da distinção e é a efetivação da condição humana da pluralidade, isto é, do viver como um ser distinto e único entre iguais (Ibid., p. 223).

Mesmo que a sociedade de massas, através de suas instituições burocráticas ou de seus modelos identitários, seja essencialmente reacionária e que a educação seja profundamente funcionalista e padronizadora do comportamento humano, ainda assim, elas não são capazes de determinar, em absoluto, o sentido da existência individual e mesmo social daqueles que chegam ao mundo todos os dias. $\mathrm{O}$ "milagre do nascimento" institui a liberdade como uma capacidade 
humana inexorável. Mesmo nas condições mais improváveis, essa liberdade possibilita que, através da ação e do discurso políticos, algo de novo aconteça no mundo, ainda que a política, propriamente, não seja mais considerada uma atividade fundamental para um determinado grupo humano. Dito de uma maneira diferente: um indivíduo pode nascer em uma região onde as leis estatísticas dizem que a mortalidade infantil é superior a todas as demais regiões de um país, onde a pobreza, em decorrência de condições de subdesenvolvimento econômico, é praticamente generalizada, onde pode-se morrer de fome ou sede, ou de alguma doença facilmente tratável pela ciência médica, onde a educação pública padece de alguns dos problemas mais graves indicados pelos especialistas, pode começar a sua vida adulta como um operário em alguma fábrica com condições de trabalho precárias, depois de ter migrado para outra região em busca de condições de vida melhores, sem ter passado por um processo formal de educação mais elevado, sendo considerado por muitos uma espécie de analfabeto e, apesar disso, a despeito de todos os fatores desfavoráveis que a racionalidade humana poderia levantar, ainda assim, pode alcançar a distinção política e a imortalidade através da história. Isso pode ser considerado um verdadeiro milagre, mas não deixa de ser um fato, ainda que a pluralidade de opiniões existentes no mundo acerca de sua estória pessoal e dos resultados de suas ações sejam diferentes, ou mesmo, divergentes. Nesse sentido específico, uma pessoa pode deixar de ser uma pessoa, transformando-se em uma ideia que tem a possibilidade de permanecer viva e liberada na memória de outros. Suas ideias e aquilo que iniciou através de ações e palavras não permanecem presas ao período delimitado de sua própria existência individual, mas ganham uma sobrevida própria através de outros que compartilham dos mesmos ideais no tempo da história. Para Arendt,

o milagre que salva o mundo, o domínio dos assuntos humanos, de sua ruína normal, "natural" é, em última análise, o fato da natalidade, no qual a faculdade da ação se radica ontologicamente. Em outras palavras, é o nascimento de novos seres humanos e o novo começo, a ação de que são capazes em virtude de terem nascido. Só a plena consciência dessa capacidade pode conferir aos assuntos humanos fé e esperança (...). É essa fé e essa esperança no mundo que encontra sua expressão talvez mais gloriosa e mais sucinta nas breves palavras com as quais os Evangelhos anunciaram sua "boa-nova": "Nasceu uma criança entre nós." (Ibid., p. 308).

O fato da natalidade, de novos seres humanos surgirem todos os dias na condição de estrangeiros, que nada sabem acerca de sua nova morada, faz com que a educação, no âmbito familiar ou escolar, se estabeleça como o meio a partir do qual os recém chegados poderão 
se sentir em casa no mundo ou nele permanecerem na condição de estrangeiros. Em seu sentido político, a natalidade aparece "como um lembrete sempre presente de que os homens, embora tenham de morrer, não nascem para morrer, mas para começar” (Ibid., p. 307). Assim, ela representa também a esperança que parece desaparecer do mundo nos momentos em que uma crise se manifesta de uma forma mais aguda.

O nascimento de uma única criança pode representar um novo começo, mas isso não significa que o mundo precise ser reiniciado toda vez que nasce um novo ser humano. $\mathrm{O}$ artifício humano também precisa ser preservado contra a irrupção do novo que tem, virtualmente, a capacidade de iniciar algo significativo para a humanidade, digno de permanecer no tempo da história, mas também, potencialmente, a capacidade para destruir completamente aquilo que foi concebido pelo esforço de todas as gerações. Por isso, o sentido da natalidade para a educação deve ser interpretado de uma maneira equilibrada, que contemple as suas possibilidades criativas, mas que considere as suas potencialidades destrutivas, estabelecendo, como uma espécie de meio termo aristotélico, a conservação do artifício humano como condição para a permanência da própria humanidade. "Exatamente em benefício daquilo que é novo e revolucionário em cada criança é que a educação precisa ser conservadora; ela deve preservar essa novidade e introduzi-la como algo novo em um mundo velho, que, por mais revolucionário que possa ser em suas ações, é sempre, do ponto de vista da geração seguinte, obsoleto e rente à destruição (ARENDT, 2003, p. 243).

No prefácio de $A$ Condição Humana, Arendt levanta o problema da alienação moderna que se manifestaria no desejo humano de um dia abandonar a Terra, expressa fartamente através da literatura de ficção científica. O tema da alienação é desenvolvido ao longo do livro e retorna no último capítulo, chamando atenção ao fato de que a vida, enquanto vida biológica, em seu sentido estrito, teria se transformado no "bem supremo" a partir da "vitória do animal laborans": "observamos essa sociedade e vivemos nela como se estivéssemos tão longe de nossa própria existência humana como estamos do infinitamente pequeno e do imensamente grande, os quais, mesmo que pudessem ser percebidos pelos instrumentos mais refinados, estão demasiado afastados de nós para fazer parte da nossa experiência" (ARENDT, 2010a, p. 404). Essa alienação decorre da falta da experiência mundana, do desaparecimento de um senso comum acerca do mundo que compartilhamos, que resultaria em um sentimento de não pertencimento ao lugar onde habita o nosso 
corpo físico. Mesmo se quiséssemos, não conseguiríamos restituir um lugar comum a todos nós, a partir de uma nova teoria pedagógica e, muito menos, através de algum decreto educacional. O problema, que reverbera no espaço da educação e na relação que estabelecemos com o mundo, foi criado do lado de fora do campo educacional.

Ainda assim, a educação encontra-se no limiar entre o novo e o velho, no espaço temporal entre o passado e o futuro que chamamos de presente. Nessa condição, sua presença pode representar um ponto de equilíbrio a partir do qual os mais novos podem caminhar em direção ao futuro com um sentido mínimo de pertencimento a um mundo no qual chegaram como estrangeiros e que poderão deixar para trás sem nenhum rastro significativo de sua passagem. Se não existirem outras gerações com capacidade e disposição para rememorar, ressignificar e projetar para o futuro esta obra, "construída pelos vivos e pelos mortos", que chamamos de mundo, ela pode, simplesmente, desaparecer. Para Arendt, "o que se passa diretamente entre os mortais, a palavra falada e todas as ações e feitos que os gregos chamaram de prakseis ou prágmata, em oposição a poiesis, fabricação, não pode nunca sobreviver ao momento de sua realização e jamais deixaria qualquer vestígio sem o auxílio da recordação" (ARENDT, 2003, p 74).

Em um certo sentido psicológico, recordamos aquilo que amamos e procuramos evitar as memórias daquilo que não nos agrada. A história está repleta de acontecimentos, decorrentes de ações engendradas pelos homens, que, certamente, não são consideradas dignas da nossa lembrança enquanto humanidade. Para nós que estamos no tempo presente, talvez o exemplo mais significativo tenha sido o holocausto, uma experiência da qual Hannah Arendt fora testemunha viva. Esquecer talvez seja o caminho mais fácil e não faltam soluções "farmacológicas" para isso, que não são a solução, propriamente, mas servem como paliativos. De qualquer modo, o esquecimento, mesmo das coisas mais indignas, pode aumentar ainda mais o sentimento de alienação, essa sensação de não pertencimento a um mundo capaz de abrigar o melhor e o pior da humanidade. A história, para Arendt, "é uma história com muitos começos, mas nenhum fim. O fim, em qualquer sentido estrito e definitivo do termo, seria apenas o desaparecimento do homem da face da Terra. Pois tudo o que um historiador chama de fim, o fim de um período, de uma tradição ou de toda uma civilização, é um novo começo para os vivos" (ARENDT, 2008, p. 343). Como ainda não dispomos dos meios necessários à realização do desejo humano de abandonar a 
Terra em direção ao espaço infinito, o fim da história humana poderia coincidir com a aniquilação total do homem e de todos os vestígios de sua experiência mundana em sua passagem pelo tempo. Certamente, dessa capacidade o homem já dispõe.

A responsabilidade que assumimos pelo mundo não é congênita, inerente ao nosso nascimento, mas é necessária à natalidade. Não é um conteúdo educacional redutível a uma teoria ou a alguma fórmula pragmática, mas o resultado direto de ações humanas, geralmente julgadas retrospectivamente. $\mathrm{O}$ que pode significar que, em educação para a responsabilidade, o exemplo possa valer mais do que as palavras, por mais fundamentadas, teórica ou empiricamente, que sejam. Daí a grande importância dada por Hannah Arendt à educação, remetida à ação do educador, que se expressa de um modo mais contundente nas palavras com as quais encerra o artigo $A$ crise na educação, uma declaração de amor que se manifesta na forma da responsabilidade que todas as pessoas deveriam assumir com o mundo onde vivem e para onde trazem as crianças todos os dias.

A educação é o ponto em que decidimos se amamos o mundo o bastante para assumirmos a responsabilidade por ele e, com tal gesto, salvá-lo da ruína que seria inevitável se não fosse a renovação e a vinda dos novos e jovens. A educação é, também, onde decidimos se amamos nossas crianças o bastante para não expulsá-las de nosso mundo e abandoná-las a seus próprios recursos, e tampouco arrancar de suas mãos a oportunidade de empreender alguma coisa nova e imprevista para nós, preparando-as em vez disso com antecedência para renovar um mundo comum (ARENDT, 2003. p. 247).

\section{REFERÊNCIAS}

ARENDT, H. A Condição Humana. São Paulo: Forense Universitária, 11ª ed. revista, 2010a.

ARENDT, H. A vida do Espírito: o pensar/o querer/o julgar. Rio de Janeiro: Relume Dumará, 2010b.

ARENDT, H. Between Past and Future. New York: Penguin Books, 2006.

ARENDT, H. Compreender: formação, exílio e totalitarismo - ensaios. São Paulo: Companhia das Letras/UFMG, 2008.

ARENDT, Hannah. Entre o passado e o futuro. São Paulo: Perspectiva, 2003.

ARENDT, H. Sobre a Revolução. São Paulo: Companhia das Letras, 2011. 
ARENDT, H. The Human Condition. Chicago: The University of Chicago Press, 1998.

BENJAMIN, W. Magia e Técnica, Arte e Política: Ensaios sobre Literatura e História da Cultura (Obras Escolhidas I). São Paulo: Brasiliense, 1985.

CESAR, M. R. de A.; DUARTE, A. Hannah Arendt: pensar a crise da educação no mundo contemporâneo. Educ. Pesqui., São Paulo, v. 36, n. 3, p. 823-837, dez. 2010 . Disponível em: <http://www.scielo.br/scielo.php?script=sci_arttext\&pid=S1517-97022010000300012\&lng= pt\&nrm=iso > . Acesso em:03 abr. 2018. http://dx.doi.org/10.1590/S1517-97022010000300012

DELEUZE, G.; GUATTARI, F. O que é a Filosofia? São Paulo: Editora 34, 2004.

DUARTE, A. Hannah Arendt e o pensamento político: a arte de distinguir e relacionar conceitos. Fortaleza, Argumentos, ano 5, n. 9, p. 39-62 - jan./jun. 2013.

LEFORD, C. Desafios da Escrita Política. São Paulo: Discurso Editorial, 1999.

HEIDEGGER, M. Ser e Tempo. Petrópolis: Vozes, 1998.

\section{NOTAS}

${ }^{1}$ Esta interpretação sobre a repercussão do espírito revolucionário na mentalidade geral dos Estados Unidos pode ser aprofundada através da leitura de Sobre a Revolução, outra importante obra de Hannah Arendt, publicada em 1963.

2 "Em consonância com a nova atmosfera de liberdade que então soprava nos Estados Unidos nos anos cinquenta, proliferaram discursos pedagógicos europeus oriundos do século XIX e das primeiras décadas do século XX, como as pedagogias libertárias dos anarcossindicalistas, a Escola Nova dos franco-genebrinos, a escola democrática de John Dewey, além das novas descobertas dos estudos de psicologia do desenvolvimento infantil" (CESAR; DUARTE, 2010, p. 830).

Submetido: $22 / 04 / 2018$

Aprovado: $22 / 07 / 2018$

Contato:

Universidade Tecnológica Federal do Paraná (UTFPR) Departamento Acadêmico de Estudos Sociais (DAESO) Av. Sete de Setembro, 3165, Bairro Rebouças Curitiba $\mid$ PR |Brasil CEP 80.230-901 